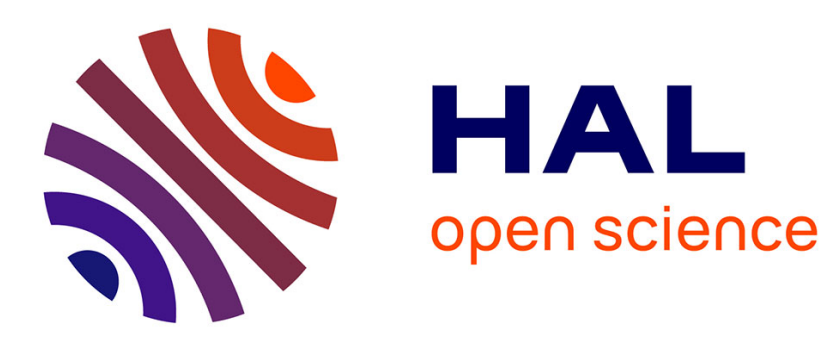

\title{
Non-smooth dynamics for an efficient simulation of the grand piano action
}

Anders Thorin, Xavier Boutillon, José Lozada, Xavier Merlhiot

\section{To cite this version:}

Anders Thorin, Xavier Boutillon, José Lozada, Xavier Merlhiot. Non-smooth dynamics for an efficient simulation of the grand piano action. Meccanica, 2017, pp.1 - 18. 10.1007/s11012-017-0641-1 . hal$01331941 \mathrm{v} 2$

\section{HAL Id: hal-01331941 \\ https://hal.science/hal-01331941v2}

Submitted on 18 Apr 2017

HAL is a multi-disciplinary open access archive for the deposit and dissemination of scientific research documents, whether they are published or not. The documents may come from teaching and research institutions in France or abroad, or from public or private research centers.
L'archive ouverte pluridisciplinaire HAL, est destinée au dépôt et à la diffusion de documents scientifiques de niveau recherche, publiés ou non, émanant des établissements d'enseignement et de recherche français ou étrangers, des laboratoires publics ou privés. 


\title{
Non-smooth dynamics for an efficient simulation of the grand piano action.
}

\author{
Anders THORIN ${ }^{1,2}$, Xavier BOUTILLON ${ }^{1}$, José LOZADA ${ }^{2}$, Xavier MERLHIOT ${ }^{3}$ \\ 1 Laboratory of Solid Mechanics (LMS), École polytechnique, Palaiseau, France \\ 2 CEA, LIST, Sensorial and Ambient Interfaces Laboratory, Gif-sur-Yvette, France \\ 3 CEA, LIST, Interactive Simulation Laboratory, Gif-sur-Yvette, France
}

Abstract Models with impact or dry friction, yielding discontinuous velocities or accelerations, have motivated research for appropriate numerical methods in the community of non-smooth dynamics. In this work, we apply such methods on the grand piano action. This multibody system has two properties of interest in terms of modelling and simulation: it is extremely sensitive to small misadjustements, and its functioning strongly relies on dry friction and stick-slip transitions - known to be crucial for the touch of the pianist. Using numerical methods of non-smooth contact dynamics, the non-smooth character of dry friction was conserved, in contrast to classical approaches based on regularization which additionally impose the somewhat arbitrary choice of a regularizing parameter. The use of such numerical method resulted in computations about a few hundred times faster than those reported in recent literature.

For the first time, the presented predictions of the piano action's simulations are forces (in particular, the reaction force of the key on the pianist's finger), instead of displacements which filter out most of the dynamical subtleties of the mechanism. The comparisons between measured and simulated forces in response to a given motion are successful, which constitutes an excellent validation of the model, from the dynamical and the haptic points of view.

Altogether, numerical methods for non-smooth contact dynamics applied to a non-smooth model of the piano action proved to be both accurate and efficient, opening doors to industrial and haptic applications of sensitive multibody systems for which dry friction is essential.

Keywords Non-smooth dynamics; piano action; multibody simulation

1 Introduction

2 Model 2

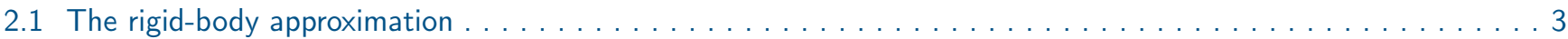

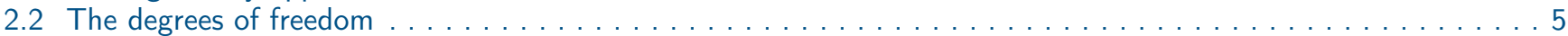

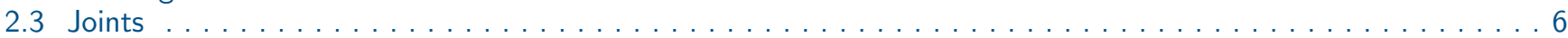

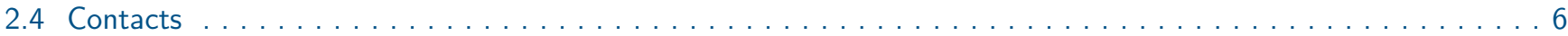

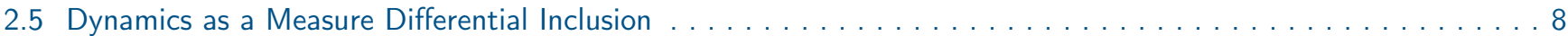

3 Measurements 9

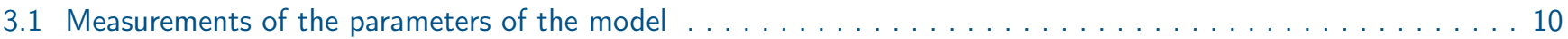

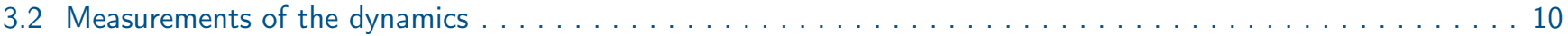

4 Simulation method $\quad 11$

5 Results and discussion $\quad 12$

6 Conclusion $\quad 15$

7 References 17

A Models for estimating the rigid body approximation for the key and the hammer $\quad 18$

1. Introduction Dynamical models with contact often include impact or dry friction, such as Coulomb friction. From the mathematical point of view, they induce discontinuities of velocities or accelerations, so that the dynamics can no longer strictly be written as a set of Ordinary Differential Equations (ODEs); for example, the velocity is not differentiable at an impact instant, since it is not continuous, hence the acceleration is not properly defined at that time. This is usually overcome by regularizing the model, i.e. approximating it somehow with a smooth model (see for example $[13,15,40]$ for the treatment of dry friction in the case of the piano action mechanism). From the numerical point of view, while this approach allows the direct use of numerical methods of ODEs, it has severe drawbacks: it can lead to stiff equations and hence the need for extremely small time steps [32], deteriorates the local order of consistency (error in one time step), the global order of accuracy and stability of the numerical scheme [1]. In short, regularizing the singularities of the ODEs is computationally quite inefficient and can lead to large numerical errors. Additionally, convergence is not ensured as the computed solutions of ODEs converges to continuous functions, loosing the non-smooth character of impact or dry friction. 
In this work, the dynamic behaviour of the piano action mechanism (see Figure 1 for a scheme and the functioning details) is modelled and simulated in quasi-real time. This multibody system has the following two particularities: i) the stick-slip transitions stemming from dry friction at the contact points and in the hinges are known to be critical for the touch of the pianist ${ }^{1}$, ii) the mechanism is very sensitive to tiny misadjustements, below the measurements error, making its modelling and simulation challenging in terms of accuracy. Additionally, there are requirements for an efficient simulation: an industrial need, because the touch of digital pianos are of very poor quality - to the extend that the top digital keyboard Yahama AvantGrand N2 includes a complete action from an actual grand piano-as well as a need in the domain of haptics - to understand why such a mechanism provides the pianist with such a high-controllability [29]. For these reasons, the piano action was modelled and simulated with special attention in the treatment of dry friction and stick-slip transitions using Measure Differential Inclusions [1] and dedicated numerical methods, developed by the non-smooth dynamics community, therefore avoiding regularization in the numerical treatments proposed in this paper. Although more mathematically sophisticated, this treatment avoids using time steps several orders of magnitude smaller than the smallest physical characteristic time. To illustrate the drawbacks of the regularizing approach, all the computation times that we found in the literature for the piano action were reported in Table 1. The most recent one ([23]) reports a simulation time of $910 \mathrm{~s}$ for a quasi-rigid body model (the backcheck wire is flexible, and an elastic model of the string is used), even though it has only a few degrees-of-freedom. The corresponding physical duration is not explicitly given, but based on the duration of the corresponding figure $(200 \mathrm{~ms})$, this would correspond to a factor of 4550 from simulated duration.

Another contribution of this work is in the validation of the model. Several dynamical models of the piano action have already been proposed, from very simple models $($ e.g. $[27,28])$ to more complex ones (e.g. $[10,13])$. An overview of these models is given in Table 2. Most of them are presented as valid by their authors although they display very different degrees of complexity. In our opinion, the output of this large body of literature is hampered with the key question of the validation of the proposed models. In [37], we showed that the validation of any complex dynamical model of the piano action can hardly be ensured by comparing measured and simulated displacements of the key, in response to a given force exerted on the key. Unfortunately, this is what most, if not all, papers adopt as their validation procedure. The rationale behind our statement goes as follows. It turns out that when a key is pushed by a realistic stroke, or a ramp of similar level and duration, or even a step of similar level, the displacement of the key is very smooth, see Fig. 8, Fig. 9 or [16]. As this displacement can be fitted by a curve with a very limited number of parameters (one or two), it is unlikely to be sensitive to the accuracy of a complex model. By contrast, the complexity of the dynamics is reflected in the reaction force of the key exerted against any simple-profile imposed displacement. The conclusion of [37] is that measured and simulated forces should be compared instead of displacements. Comparing measured to simulated accelerations may be an alternative provided that a level of force comparable to at least a mezzoforte musical level is used.

The model is provided in Sect. 2, the measurements of the mechanism are described Sect. 3, details on the non-smooth simulation methods are detailed in Sect. 4 and finally, measurements and simulations are compared in Sect. 5.

Model A piano keyboard can be seen as an interface between the pianist and the vibrating ensemble (strings and soundboard). It consists in a set of nearly identical planar actions, each associated with one single note (a note is produced by 1, 2 or 3 coupled strings). As an interface, the role of one piano action (Figure 1) is to transform the pianist gesture into the motion of a hammer towards the strings (description of the sequence in the caption of Figure 1, also illustrated in Figure 11). Among other requirements (maintenance, ease of making, etc.), a piano action is designed as to favour the precision with which the pianist controls the velocity of the hammer when it hits the strings and the instant at which this contact occurs. One of its fundamental property is to free the hammer from the mechanism before it hits the strings (escapement) and to catch it afterwards, further away from the string than the position at which it has escaped from the mechanism. This guarantees that the pianist can push the key without preventing the

\footnotetext{
${ }^{1}$ The non-smooth character of the key action is also used by technicians during the adjustment procedure.
} 


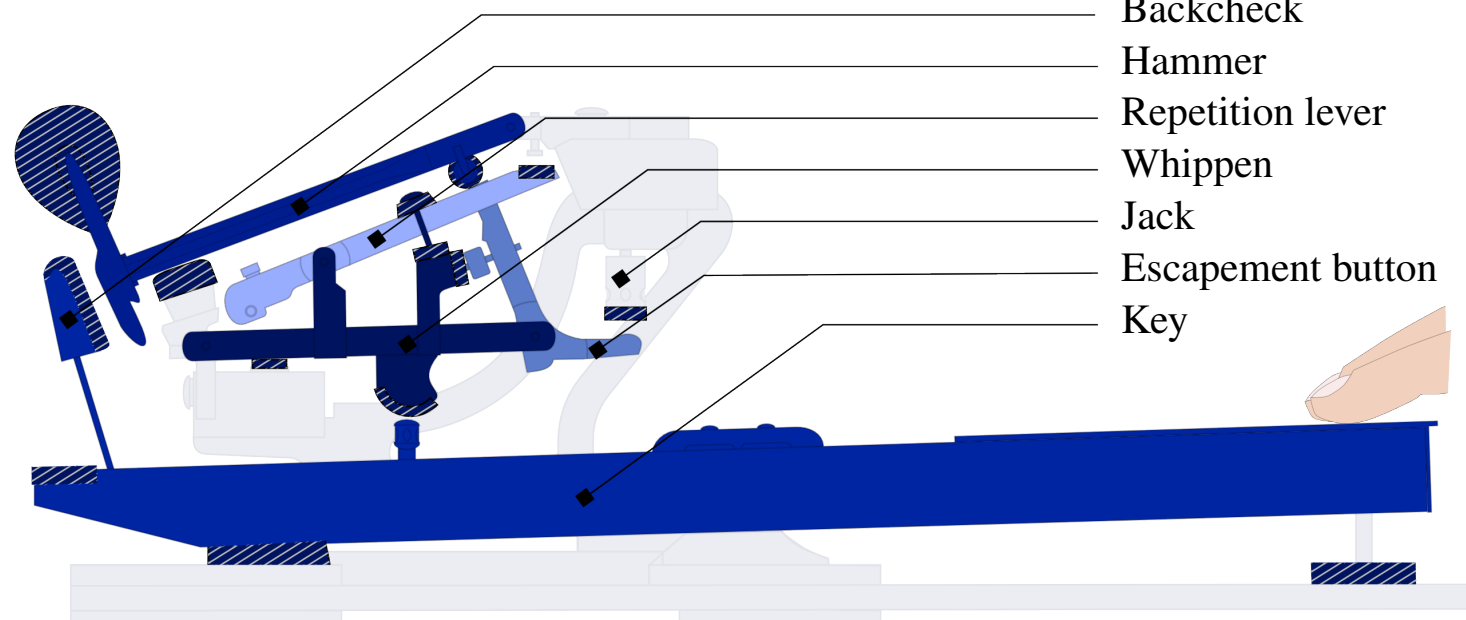

Figure 1: Scheme of an action, without the damper. The key, the whippen and the hammer rotate around fixed axes (with a slight complication for the key) whereas the axes of the lever and the jack are attached to the whippen. Under the push exerted by the pianist (on the right end of the key), the key pivots and lifts the whippen. The \{whippen-lever-jack\} assembly then lifts the hammer until the jack reaches the escapement button. At that time, the jack begins to pivot (with respect to the whippen). This motion makes the hammer escape. The key and the \{whippen-lever-jack\} ensemble continue the same motion until the key is blocked by the punch rail (bottom right felt of the diagram) whereas the hammer travels on its own towards the strings, hits them, and comes back on the lever. Since the jack is now out of the way of the roller, the hammer can push the lever which rotates clockwise (with respect to the whippen) until the tail of the hammer meets the backcheck and stops its motion. The two functions-escapement of the hammer, catch away from the strings after hammer-string contact-are ensured. Subtleties of the repetition are not discussed here. More details of the main steps are given in Fig. 11.

strings from vibrating. This article focuses on the grand piano action.

The present model is based on the same approximations and physical components as complex models available in the literature (see Sect. 2.1 for the rigid-body approximation, Sect. 2.2 for the general description of the degrees of freedom, Sect. 2.3 and Sect. 2.4 for the treatment of joints and contacts). It is described by means of Measure Differential Inclusions (Sect. 2.5).

We consider the wooden and other solid parts of the piano action as five bodies moving in a plane (two-dimensional model).Since modelling the damper does not seem to present special difficulties, this part has been ignored in this paper for the sake of simplicity and clarity of the conclusions. Its inclusion in the model is left for future studies. By piano action, in what follows, we understand without damping, corresponding to the musical situation when the forte pedal is engaged.

2.1. The rigid-body approximation All the bodies are supposed to be rigid. Some papers in the literature have examined and dealt with the flexibility of the hammer-shank and it has also been argued that the flexibility of the key might be felt by the pianists $[7,16]$. For these reasons, the degree to which the rigid-body approximation is valid is examined here. One considers that the approximation alters the dynamics in a consistent way when (a) the period of the first mode of vibration of one piece is longer than $5 \mathrm{~ms}$, corresponding to one fourth of the duration of the fastest keystroke $(\approx 20 \mathrm{~ms}$ in the forte nuance) and (b) the piece itself is significantly flexible compared to the flexibility induced by its environment (namely, the felts).

First, a very rough approximation of the period of the first mode of vibration of each piece is estimated using a clamped-beam model. For each body, the section of the equivalent beam is chosen rectangular of width $b$ and height $h$ corresponding to the dimensions of the body's smallest cross section, so that the area is $S=b h$ and the moment of inertia of the section is $I=b h^{3} / 12$. The density and Young's modulus 


\begin{tabular}{|c|c|}
\hline $\begin{array}{l}\text { Van den Berghe et } \\
\text { al. [39] }\end{array}$ & $\begin{array}{l}\text { "Because ours is a stiff system and the action topology is changing during simulation (e.g., depending } \\
\text { on the position of the action, the hammer looses contact with the jack), a simulation of } 1 \text { sec in real } \\
\text { life takes about } 4 \text { hours on a 486DX33 IBM PC-compatible computer. This is one reason why we are } \\
\text { working on a reduced-parameter model." } \\
\text { "Running on a Digital Equipment Corp. DEC 5000/33 work- station, the simulation of } 1 \text { sec in real } \\
\text { life took about } 15 \mathrm{sec} \text { with the reduced model." }\end{array}$ \\
\hline Oboe [27] & $\begin{array}{l}\text { "The realization of a multi-instrument active keyboard may require the design of a complex dynamic } \\
\text { simulator, in which all parts composing the real mechanism are included. This approach, however, is } \\
\text { very expensive in terms of computation and may be unsuitable for real-time operation." }\end{array}$ \\
\hline Izadbakhsh [15] & $\begin{array}{l}\text { "Running a complete simulation, for the system with the force profile in Figure } 2.11 \text { as the input to the } \\
\text { piano action, requires about } 75 \text { minutes on a } 2.4 \mathrm{GHz} \text { PC computer. This is true for the case when the } \\
\text { hammer shank and the connection of the key to the ground have been modelled with a flexible beam } \\
\text { and a prismatic-revolute joint, respectively. However, the Maple environment is not the most efficient } \\
\text { platform for running simulations in terms of time, and the simulation time can be significantly reduced } \\
\text { by implementing the model and solvers in a dedicated, compiled language such as C." }\end{array}$ \\
\hline $\begin{array}{l}\text { Masoudi and Bir- } \\
\text { kett [23] }\end{array}$ & $\begin{array}{l}\text { "The computational cost of the flexible shank is not insignificant. Simulation process (CPU) time is } \\
\text { almost doubled }(1720 \mathrm{~s}) \text { as compared to that for a rigid hammer shank }(910 \mathrm{~s}) . "\end{array}$ \\
\hline
\end{tabular}

Table 1: Excerpts of the literature relating to the duration of the simulations.

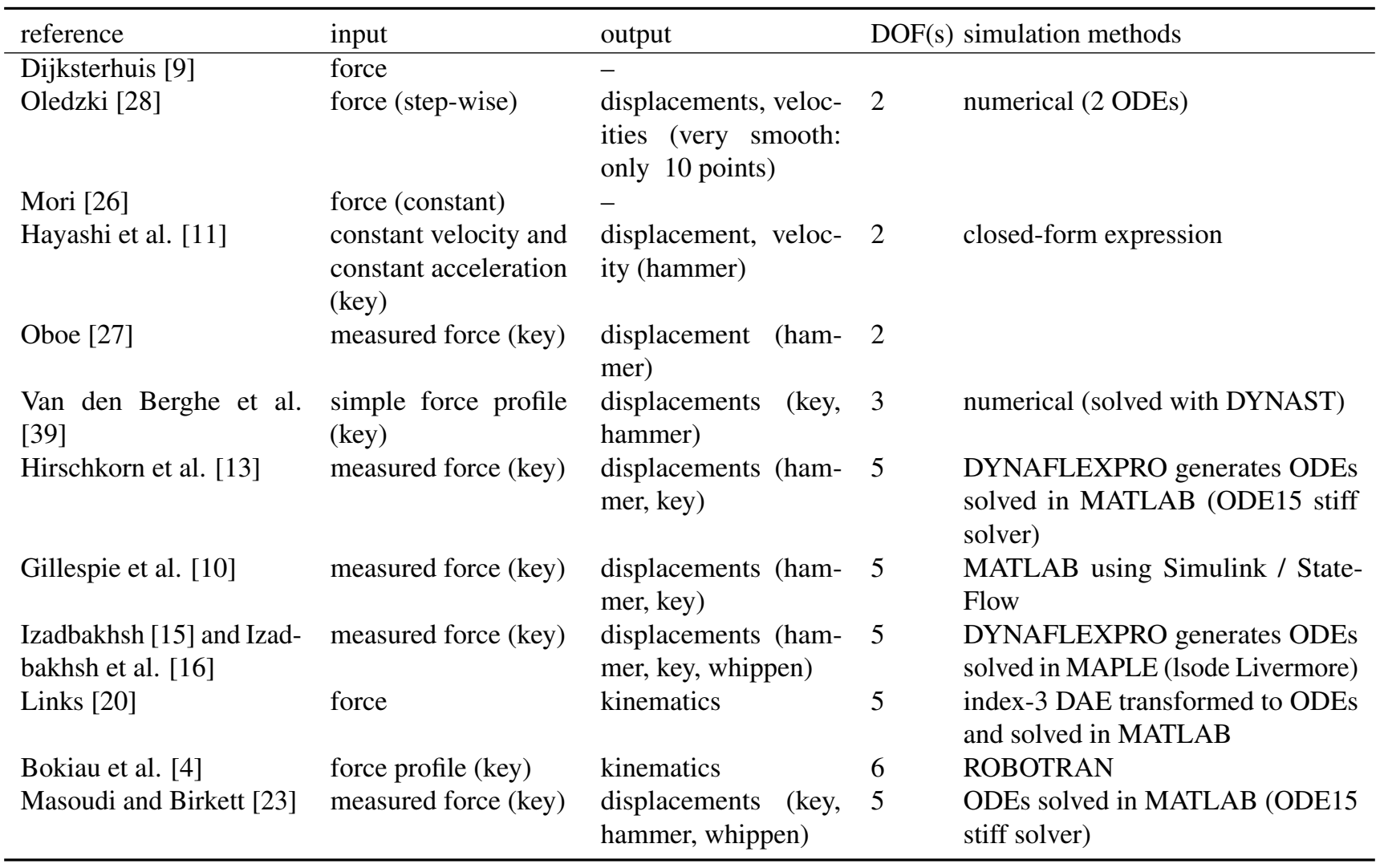

Table 2: Schematic literature review of the grand piano action models

along the grain correspond to those of the hornbeam (case of this Renner action [35]) or hard maple: $\rho \approx 750 \mathrm{~kg} \mathrm{~m}^{-3}$ and $E \approx 12 \mathrm{GPa}$. The first modal frequency of a clamped-free beam is given by

$$
f_{1}=\frac{1.875^{2}}{2 \pi} \frac{1}{L^{2}} \sqrt{\frac{E I}{\rho S}}
$$

where $L$ is the length of the beam. Results are reported in Tab. 3 and call for a more thorough study of the key and the hammer (by inspection, it is clear that the flexibility of the other pieces is very small).

For these two pieces, slightly more elaborate models are presented in Appendix A. The first modal frequencies are estimated as $f_{\text {key }}=355 \mathrm{~Hz}$ and $f_{\text {hammer }}=39 \mathrm{~Hz}$, corresponding to $\left(f_{\text {key }} \tau\right)^{-1}=0.56$ and $\left(f_{\text {hammer }} \tau\right)^{-1}=5.1$. The ratio is correct for the key but not for the hammer. This may be related with the 


\begin{tabular}{lccc|c}
\hline piece (cf. Fig. 1) & $L(\mathrm{~m})$ & $b(\mathrm{~m})$ & $h(\mathrm{~m})$ & $1 /\left(f_{1} \tau\right)$ \\
key & 0.380 & 0.015 & 0.025 & 1.8 \\
whippen & 0.060 & 0.010 & 0.008 & 0.14 \\
jack & 0.025 & 0.005 & 0.005 & 0.039 \\
lever & 0.030 & 0.005 & 0.005 & 0.056 \\
hammer & 0.130 & 0.005 & 0.005 & 1.0 \\
damper & 0.070 & 0.010 & 0.02 & 0.076 \\
\hline
\end{tabular}

Table 3: Order of magnitude of the approximate dynamical characteristic parameters of each element of the action.

tuners' practice of "sounding the hammer shanks". ${ }^{2}$

As mentioned above, the rigid body approximation may be invalid for the hammer and the key if their flexibility (see Appendix A for the precise definition) is significantly lower than the apparent flexibility induced by felts. The situation is analysed in details in the second part of Appendix A. Considering rigid boundaries and linear elasticity leads to $\psi_{\text {key }}^{\mathrm{e}}=1.5 \times 10^{-5} \mathrm{~m} \mathrm{~N}^{-1}$ and $\psi_{\text {hammer }}^{\mathrm{e}}=1.2 \times 10^{-3} \mathrm{~m} \mathrm{~N}^{-1}$. Taking into account felts at the boundary of a rigid model yields $\psi_{\text {key }}^{\mathrm{f}}=9.5 \times 10^{-5} \mathrm{~m} \mathrm{~N}^{-1}$ and $\psi_{\text {hammer }}^{\mathrm{f}}=4.8 \times 10^{-3} \mathrm{~m} \mathrm{~N}^{-1}$. In other words, felts contribute more to flexibility than elasticity in a static model of the piano action, by at least factors of 6 and 4 for the key and hammer, respectively. A fortiori, the influence of the flexibilities of the key and of the hammer is even less in a mobile piano action.

In conclusion, due to its relatively low first modal frequency, the vibrations of the key and the hammer may influence the dynamics of the whole mechanism. However, their relatively small flexibility leads to the assumption that this influence is rather small, at least compared to the level of the differences which will be observed between simulations and measurements. The dynamics of the hammer has been studied in [2] and taken into account in [16]. The former study had concluded that no influence of the dynamics of the hammer on the sound could be predicted. The author of the latter study concludes from force-driven simulations that the only observed significant influence of the flexibility of the hammer shank occurs during the contact with the string. This is consistent with the evaluation presented here of the rigid body approximation. As far as haptics is concerned, the most important phases are before escapement and when the key meets the front rail punching. Because the hammer has already escaped from the mechanism when it hits the string, the flexibility of the hammer is assumed to have no effect on the touch and is not taken into account here. For the same reason, fine modelling of the hammer-string interaction is not relevant in this work; a simple ad hoc Newton elastic law suffices to reproduce the kinematic measurements of the velocities of the hammer after it escapes the mechanism and before it is captured again.

2.2. The degrees of freedom Within the frame of the rigid-body approximation, each element except the key is rotating around a mechanical axis inserted in the action frame or in the whippen. The motion of each body is considered to have only one degree-of-freedom described by $\theta_{\mathrm{X}}$ where $\mathrm{X}$ can be W, J, L or H for the Whippen, the Jack, the repetition Lever or the Hammer, respectively.

The fixture of the key-a vertical thick pin, called balance rail key pin which goes throughout a hole in the key-represents a typical traditional wood-work. In this case, two degrees of freedom are involved: rotation around a horizontal axis and vertical translation. The vertical motion is limited by the small piece of felt between the main frame and the key. The rotational motion is restrained by the elasticity of wood and by the friction between wood and the balance rail key pin. At an early stage of this study, it proved difficult to repeat the experiments to the degree of precision that was desirable for comparing them with the simulations of the model. Overcoming it would have required estimating separately rotation and translation. Instead, we preferred to block the translation motion of the key (by replacing the small felt with a metallic ring of the same thickness) when measuring the dynamics and to prescribe that the motion

\footnotetext{
${ }^{2}$ According to piano technicians, the sound of a note is sensitive to the "quality" of the shank. In order to select shanks (before gluing the hammer's head), a common practice consists in listening to the sound they emit when thrown on the floor (for example).
} 


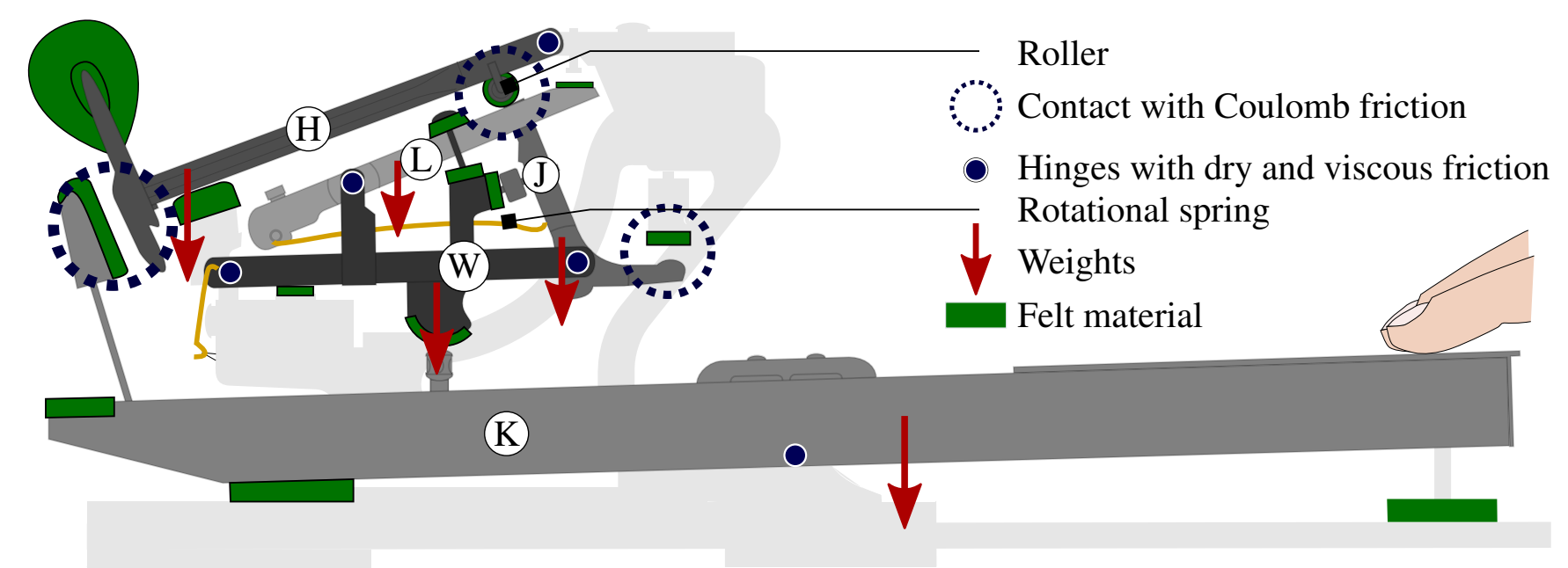

Figure 2: Schematic representation of the physical elements considered in the model.

of the key is a rotation around a fixed axis in the simulation. Although such a modification would not be acceptable in practice (it makes the action fairly noisy), this is yet a very minor alteration of the action from the mechanical standpoint.

2.3. Joints The hinge joints (blue dots in Figure 2) are modelled as dry- and viscous-frictional elements. Dry friction torques are taken as

$$
\begin{gathered}
C_{\mathrm{d}}(\theta)=c_{\mathrm{d}} \operatorname{sign} \dot{\theta} \\
\text { sign }: \dot{\theta} \in \mathbb{R} \longmapsto\left\{\begin{array}{lll}
-1 & \text { if } \quad \dot{\theta}<0 \\
{[-1,1]} & \text { if } \quad \dot{\theta}=0 \\
1 & \text { if } \quad \dot{\theta}>0
\end{array}\right.
\end{gathered}
$$

where $\dot{\theta}$ is the corresponding angular velocity, $c_{\mathrm{d}}$ is a coefficient determined experimentally (see Sect. 3) and sign is a set-valued function (see Sect. 4 for the numerical treatment within the framework of non-smooth dynamics)]. Viscous friction torques are given by:

$$
C_{\mathrm{v}}(\theta)=c_{\mathrm{v}} \dot{\theta}
$$

where $c_{\mathrm{v}}$ is also a coefficient determined experimentally (see Sect. 3).

In order to ensure the repetition capability, the jack and the repetition lever must be pulled back to their resting position on the whippen once the forces exerted by escapement button and the hammer (when blocked by the backcheck) have vanished. This function is ensured by two springs (which may be combined into one single metal thin rod as in Figure 2). In some piano actions (including ours), a spring is also inserted between the whippen and the main frame. The torque exerted by any of these springs is generically given by

$$
C_{\mathrm{s}}(\theta)=\kappa\left(\theta-\theta_{0}\right)
$$

where $\kappa$ is the stiffness of the spring, $\theta$ its angular extension and $\theta_{0}$ its resting angular position (see Sect. 3 for values).

2.4. Contacts Twelve different contacts may occur in this 5-dof-system. There is a felt in each of the contact zones, which somehow smoothens contact forces in the normal direction. Note that contrary to a regularisation approach where the numerical efficiency directly depends on the stiffness of the felts, numerical methods adopted here allow for an efficient simulation for any stiffness and even rigid contacts, opening doors to efficient sensitivity analyses. In the model, a felt is treated as a very small mass attached to its supporting element by means of a nonlinear viscous spring (Kelvin-Voigt model). The following phenomenological visco-elastic compression law has been retained [6]:

$$
F_{\text {felt }}(\delta)=k \delta^{r}+b \delta^{2} \dot{\delta}
$$


where $\delta$ denotes the compression of the felt and $F_{\text {felt }}$ denotes the corresponding reaction force of the felt. References for experimental estimations for the parameters $k, r$ and $b$ are given in Sect. 3. Since [5], it has been observed that the loading curves of the hammer felt were nearly velocity-independent. The small but significant dependency in velocity $(b \neq 0)$ has been investigated thoroughly by several researchers, particularly in papers by Stulov (see for example [34]). It must be emphasized that the purpose of this felt model (with only three parameters) is to account for the felt behaviour in a large dynamical range, both on compression and on the rate of compression. This range must be at least as large as the range of the dynamical levels encountered in piano playing between the piano and the forte levels. The interest and justification of this heuristic model are that it is simple to handle and that it mimicks direct dynamical experiments on the felts in use in the piano action fairly closely.

Friction in the tangential direction is considered only for the three contacts circled in Figure 2. Friction between the hammer and the backcheck is crucial for stopping the motion of the hammer after hitting the string. Friction between the jack and the roller is easily felt by the pianist and must also be considered in the model, because the piano technicians adjust it carefully. Additionally, we chose to take friction into account between the jack and the escapement button. Friction is ignored in the other contacts which are subject to a rather small translational motion. The friction law is taken as in Eq. (2.2):

$$
F_{\mathrm{d}}(v)=f_{\mathrm{d}} \operatorname{sign} v
$$

where $v$ is the tangential velocity and $f_{\mathrm{d}}$ the dry friction coefficient.

The duration of contact is longer than one sampling period, calling for the simulation of the compression and possibly, the decompression of the felts. The contact for each of the twelve felts is treated as follows: a small additional rigid body (labelled "A" in Figure 3), a prismatic joint ("P") and a visco-elastic element "V" (Kelvin-Voigt model) are inserted between the felt support and the contacting body ("B"). A unilateral constraint prevents this additional body " $\mathrm{A}$ " from penetrating the contacting body "B". Additionally, an impact law must be introduced for this auxiliary body "A", that we choose to be inelastic to allow permanent contact phases. The inelastic impact law dissipates kinetic energy of the contacting mass, however very little energy is dissipated if the mass of the auxiliary body " $\mathrm{A}$ " is much smaller than the mass of its supporting body. Here, this condition was met by taking arbitrarily $1 \mathrm{mg}$ for the mass of all the "A" elements.

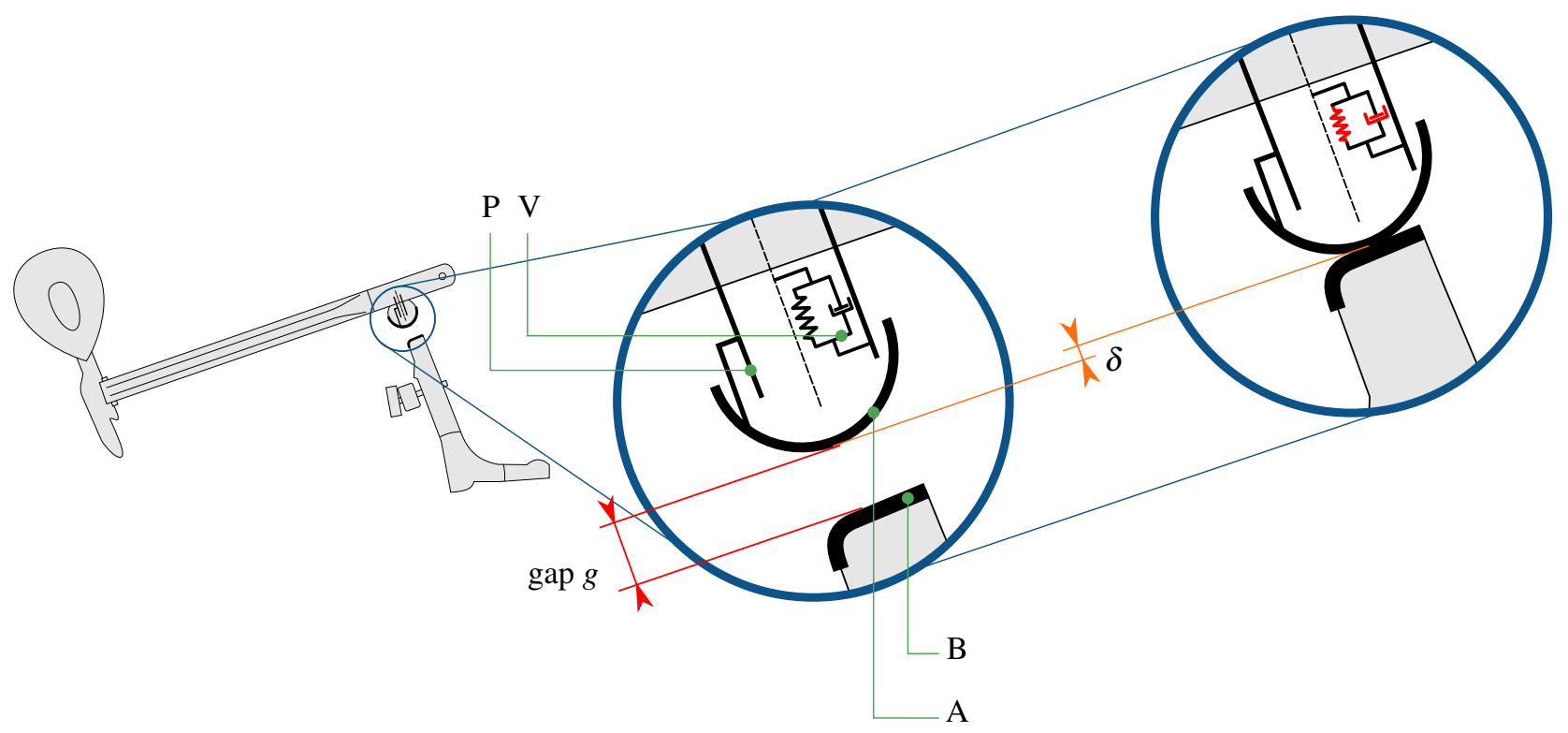

Figure 3: Generic model of the contact between two pieces, here the roller and the jack. The distance, or gap, between the two pieces is $g \geq 0$ (condition of non-penetration). The compression of the felt is $\delta \geq 0$ (unilateral constraint).

The twelve contacts are described with geometries as simple as possible, similarly to [13]. The geometries are reported in Table 4. The backcheck-hammer contact geometry is described by two circles. 
The jack-roller contact geometry consists of a two perpendicular lines joined with a circular arc. All the other contacts are described with a circle and a line segment.

\begin{tabular}{lrrc}
\hline \multicolumn{1}{c}{ Geometries } & & Quantity \\
backcheck-hammer & & & 1 \\
jack-roller & & & 1 \\
all other contacts & & & 10 \\
\hline
\end{tabular}

Table 4: Simplified geometry of the contact zones

2.5. Dynamics as a Measure Differential Inclusion The dry friction model is intrinsically non-smooth in the sense that it induces acceleration discontinuities at stick-slip transitions. It cannot be written as a single-valued function because the friction force (or torque) can take an infinity of values for a zero velocity, hence an infinity of possible static states in a sticking phase. To the best of the authors' knowledge, all the models in the piano literature that include dry friction $([12,13,15]$, etc.) are simulated by regularizing the friction law. This goes along with the following problems:

- The sticking phase disappears and the stick-slip transitions are lost: the dry friction force or torque vanishes when the velocity vanishes.

- At least one non-physical parameter (the so-called regularization parameter) is introduced, weakening the robustness of the simulation. This might prove critical in a sensitivity analysis.

- Spurious oscillations can occur if the regularized zone is too narrow, or inaccurate results are obtained if the regularized zone is too wide.

- Reduction of spurious oscillations calls for a reduction of the time step, resulting in an increase of computation time. Time step reduction might also be required to ensure stability of the chosen numerical scheme.

- The condition number of the matrices involved increases as the slope of the regularized function increases.

Some of the above drawbacks of regularization cannot be observed in the force-driven simulations reported in the literature because they are masked by the intrinsic smoothness of the resulting motions, as mentioned in the introduction.

One simple example of the interest of not regularizing is the following. A basic adjustment of the key mechanism consists in measuring the maximum mass to be put on the key without initiating the down-motion from the resting position and conversely, the minimum mass that prevents the up-motion from the down-position. The result directly depends on the dry friction coefficient in the hinges. However, this simple test cannot be simulated with a regularized friction law.

The counterpart of not regularizing is that the model cannot be formulated as Ordinary Differential Equations (ODEs) for which a large variety of commercial software applications exists. The reason for this is that non-smooth laws cannot be properly captured captured with twice-differentiable functions of time because of the discontinuities in acceleration or velocity. Several mathematical frameworks may be used to describe the non-smooth model, mainly Measured Differential Inclusion (MDI), Variational Inequalities (VI) or Nonlinear Complementary Problem (NLCP): a general presentation is given in [1]. We chose to express the model of the grand piano action in terms of a Measure Differential Inclusion (MDI), following $[1,18,32]$. The mathematical foundations are given in the cited references. In summary, this formalism can be seen as an extension of the usual dynamical equations (ODEs) to non-smooth laws. In the inclusions below, the $\in$ symbol underlines a difference of mathematical nature: the left-hand side of $\in$ is an array of scalar numbers, while the right-hand side is an array of set-valued functions.

The proposed model is given by the following inclusions:

- Internal moments (dry friction in hinges) given generically by Eq. (2.2) are now written in a condensed way as:

$$
\mathbf{r}_{P} \in \mathbf{c}_{\mathrm{d}} \operatorname{sign}(\dot{\mathbf{x}})
$$


where $\mathbf{r}_{P}$ (now standing for the torques $C_{\mathrm{d}}$ ) belongs to $\mathbb{R}^{12}$ and $\operatorname{sign}(\dot{\mathbf{x}})$ is an array of components $\operatorname{sign}\left(\dot{x}_{i}\right)$.

- The twelve gaps between bodies (condensed with the same writing convention as above) remain positive (unilateral contact condition or condition of non-penetration) which writes mathematically as:

$$
\mathbf{g}(\mathbf{x}) \in \mathbb{R}^{+12}
$$

- The normal reaction forces at contacts are given in a compact way by:

$$
-\mathbf{r}_{\mathrm{N}} \in \mathscr{N}_{\mathbb{R}^{+12}}(\mathbf{g}(\mathbf{x}))
$$

which means that reaction forces are either 0 (no contact, $g(\mathbf{x})>0$ ) or negative (compression, if one contact occurs, i.e. one component $g(\mathbf{x})=0)$. The expression $\mathscr{N}_{\mathbb{R}^{+}}(\mathbf{g}(\mathbf{x}))$ denotes the normal cone to the convex set $\mathbb{R}^{+12}$ in $\mathbf{g}(\mathbf{x}) \in \mathbb{R}^{+12}$ (see e.g. [30] for general knowledge about convex analysis).

- The tangential reaction forces (Coulomb friction) are written without writing the usual logical disjunction explicitly:

$$
-\left(\mathbf{H}^{\top}(\mathbf{x}) \mathbf{v}\right)_{3 i-2,3 i-1} \in \mathscr{N}_{\mathscr{B}}\left(\mu\left(\mathbf{r}_{\mathrm{N}}\right)_{i}\right)\left(\left(\mathbf{r}_{T}\right)_{2 i-1,2 i}\right)
$$

where $\mathbf{H}^{\top}$ is the geometric operator which yields the relative velocities in the (local) contact frame as a function of the generalized velocities. This slightly cumbersome inclusion simply relates local velocities to normal forces and to reaction forces imposed by the Coulomb friction model. For each contact $i$, the indices $3 i-2$ and $3 i-1$ refer to the tangential components of the velocity, $\left(\mathbf{r}_{\mathrm{N}}\right)_{i}$ is the normal reaction force and $\left(\mathbf{r}_{T}\right)_{2 i-1,2 i}$ is the reaction force in the tangential direction.

These four inclusions can be expressed generically (Eq. (2.14)) as one inclusion in a set $K$. Altogether, the dynamics is written as the following Measure Differential Inclusion (MDI):

$$
\left\{\begin{array}{l}
\mathbf{M}(\mathbf{x}) \mathrm{d} \mathbf{v}=\mathbf{F}^{\star}(\mathbf{x}, \dot{\mathbf{x}}, t) \mathrm{d} t+\mathbf{H}(\mathbf{x}) \mathrm{d} \mathbf{i} \\
\mathbf{v}^{+}=(\dot{\mathbf{x}})^{+} \\
\left(\mathbf{g}(\mathbf{x}), \mathbf{H}^{\top}(\mathbf{x}) \mathbf{v}^{+}, \mathrm{d} \mathbf{i}\right) \in K
\end{array}\right.
$$

The (non-smooth) dynamics is expressed by Eq. (2.12) where dv and di are vector-valued measures on $\mathbb{R}$ and can therefore be non-smooth. All the smooth terms, such as non-linear dynamic terms or viscous friction, are included in $\mathbf{F}^{\star}$. The non-restrictive assumption that the local variations of the velocities $\mathbf{v}$ are bounded implies that velocities have right (and left) limits at any time [14]; the dynamics can therefore be written as a function of right-continuous bounded variations, which explains the "+" sign in Eq. (2.13). Eq. (2.14) gathers the non-smooth laws (tangential Coulomb friction at contact points, joint friction, unilateral contacts) and equality constraints.

3. Measurements Measurements are focused on the key because that is where the pianist interacts with the action. Additional measurements on each piece improve the comparison with the results of simulation. The measurements were done on an isolated action by Renner (Figure 4) equipped as follows (Figure 5):

- a piston compressing a piece of silicone, between the end of the key and the finger. This auxiliary device was needed for technical reasons associated with the simulation algorithm as explained in Sect. 4,

- patches with black-and-white patterns on each rigid body, aimed at measuring their motion by optical means,

- position laser sensors (top of the piston and key),

- acceleration and force sensors.

The values of the model's parameters are given in [36], Chapter 4, Section 5 (p. 60-68). 


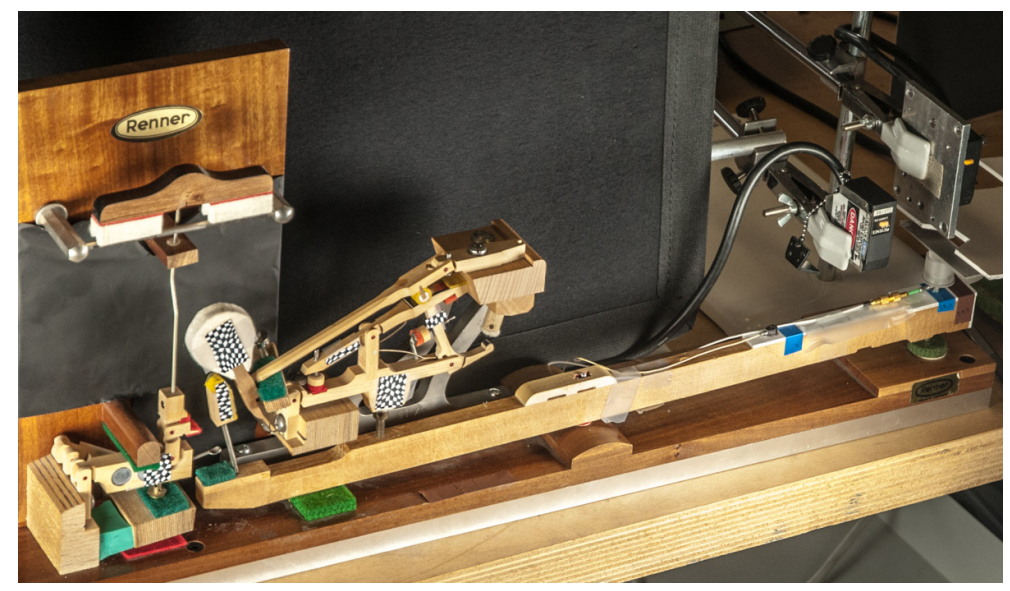

Figure 4: Overview of the experimental setting.

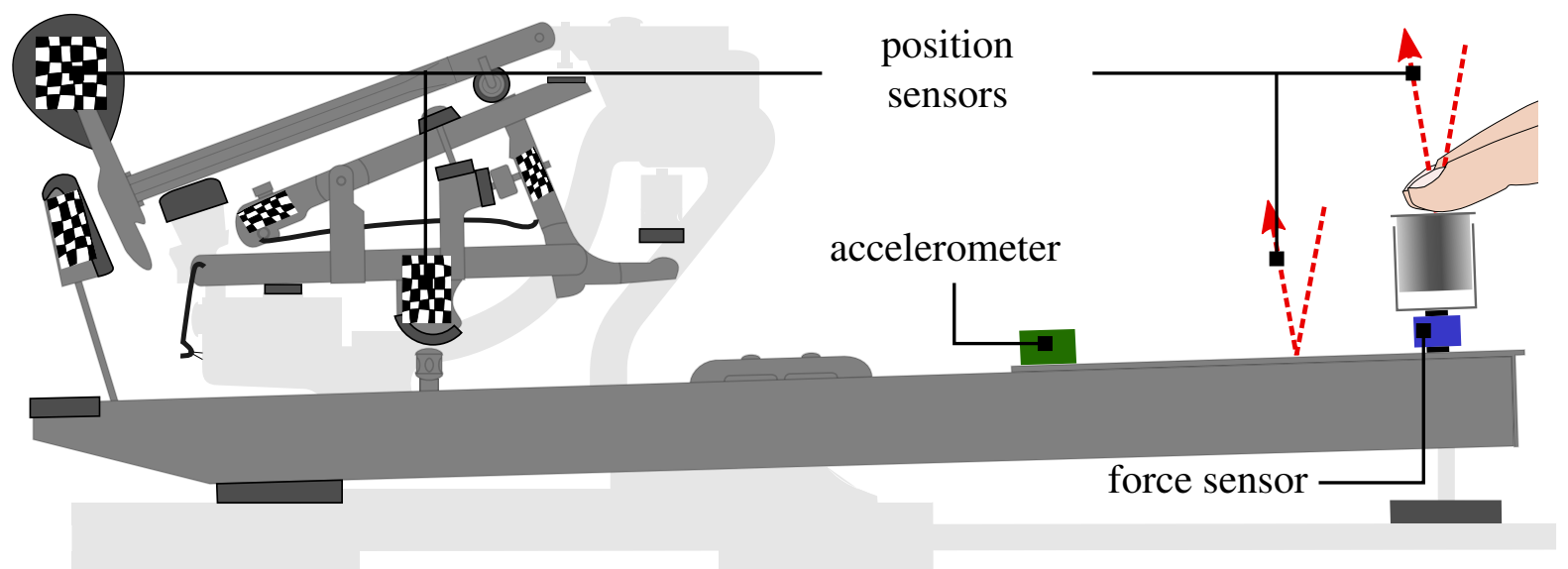

Figure 5: Location of the different measurement devices (see text).

3.1. Measurements of the parameters of the model The geometrical quantities (positions and angles) were estimated by analysing two high-definition pictures: a view of the complete mechanism and a close-view of the hammer and the whippen-jack-lever assembly, at rest. The photographs were taken at $3 \mathrm{~m}$ from the action to reduce the parallax effect, and the lens distortion was corrected using the Optics Pro software by DxO. Because of the time-worn felts of the used action and as a double-check, additional measurements were done with a dial caliper.

Parameters relative to bilateral constraints, namely the dry friction coefficient $c_{\mathrm{d}}$ and the viscous friction coefficient $c_{\mathrm{v}}$ on the various pivots, were taken from the measurements performed on a different copy of the same action model (see [21]; the detailed measurement protocol is given in Chapter 3). The felt parameters (unilateral constraints) were identified in [6], measured again in [21] and reported in [36] (p. 67). In both cases, for a given felt, the identification of the parameters consisted in minimizing a cost functional measuring the distance between a series of dynamical measurements from piano to forte and the prediction of the model. This resulted in one single set of three parameters for each felt, which captures the corresponding range of dynamical levels.

The measurements of the inertial parameters (center of gravity, mass and rotational inertia) as well as the parameters of the springs (rest angles $\theta_{0}$ and stiffness $C_{\mathrm{s}}$ ) were also measured in [21] and reported in [36] (p. 60-68).

3.2. Measurements of the dynamics Since the variations of $\theta_{\mathrm{K}}$ remain small, rotational quantities are obtained by axial measurements on the key.

The displacements of the key and of the top of the piston were measured by laser sensors (Keyence LB12 with LB72 amplifier units), positioned as shown in Figure 5. What can be interpreted in the data sheet as an integration time was set to $0.15 \mathrm{~ms}$, coming along with a resolution of $50 \mu \mathrm{m}$. The sensitivity of each sensor was estimated statically by means of a graduated marking gauge $\left(0.398 \mathrm{~V} \mathrm{~mm}^{-1}\right.$ and $0.449 \mathrm{~V} \mathrm{~mm}^{-1}$ ). 
The acceleration of the key was measured with a piezoelectric accelerometer (Endevco R 2250A, mass $0.4 \mathrm{~g}$, sensitivity $0.316 \mathrm{~V} \mathrm{~m}^{-1} \mathrm{~s}^{-2}$ ), placed midway between the center of rotation of the key and the piston (finger-end) and associated with a Brüel \& Kjær Nexus conditioning amplifier and filter $(0.1 \mathrm{~Hz}-3 \mathrm{kHz})$.

Since the model includes viscosity, the key velocity had to be estimated. The velocity was obtained numerically by two independent algorithms: integration of the acceleration signal (after removal of the average value of the signal at rest) and differentiation of the position signal, using a total-variation regularisation [8] (here: 30 iterations, 200 sub-iterations, a regularization parameter of $510^{-5}$ and $\varepsilon=10^{-9}$ ). In practice, choosing one or the other estimation of the velocity had very small influence on the simulation results. The velocity was estimated using the algorithm of total-variation regularization.

Additional measurements of the positions of each body were carried out to estimate their qualitative evolutions with respect to time: of special interest are the instants of significant variations in $\ddot{\theta}$ which should correspond with changes in contacts. The positions were measured using a high-speed and highresolution camera (Simi HCC-1000, equipped with four CMOS sensors, $923 \mathrm{fps}, 1024 \mathrm{px} \times 512 \mathrm{px}$ ). The camera acquisition was synchronized with the other measuring devices. The images (successive positions of the patches) were treated with the KLT tracking algorithm [22, 38] using the CRToolbox implementation [3]. An illustration of the tracking is given in Figure 6.
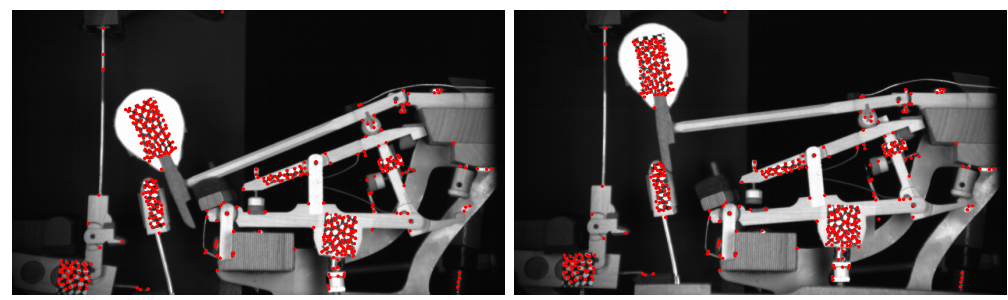

Figure 6: Illustration of the KLT tracking algorithm used to measure the qualitative evolution of the bodies positions with time. Left: resting position. Right : After hammer-string contact.

The force exerted on the end of the key is measured with a light-weight $(1.2 \mathrm{~g})$ piezoelectric sensor (Kistler 9211), with a charge amplifier (Kistler 5015) operating in the frequency range $[1 \mathrm{~Hz}-3 \mathrm{kHz}]$ (the data sheet indicates $f_{\text {cut-off }} \ll 1 \mathrm{~Hz}$ ).

According to the data sheet provided by Kistler, the sensitivity of the sensor is $10 \mathrm{mN}$, the nonlinearity and hysteresis effects are contained within $\pm 1 \%$ of the full scale output (thus depending on the choice made on the charge amplifier for the operating range). In our experiments, this scale was usually adjusted to $10 \mathrm{~N}$.

The signal is sampled at $50 \mathrm{kHz}$ (ADC USB-6211 by National Instruments, also used for the motion signals). Sampling begins about $1 \mathrm{~s}$ before the keystroke in order to perform the following post-treatments: the $50 \mathrm{~Hz}$ component is identified in phase and in amplitude on the force-data preceding the keystroke and is removed from the entire time series. The $0 \mathrm{~Hz}$ component is identified and removed in the same way.

4. Simulation method The simulations were done with XDE (eXtended Dynamic Engine), a software developed at CEA LIST for industrial virtual prototyping and simulations in robotics. This software is available, on request, to members of the academic community for research purposes. The part we used is XDE Physics, a $\mathrm{C}++$ development kit consisting in a kernel for interactive mechanical simulation of rigid multibody systems with kinematic constraints, intermittent contacts and dry friction. It includes efficient methods for collision detection. In this paragraph, we expose the numerical scheme and methods that we used. More details are given in [25].

The MDI Eqs. (2.12), (2.13) and (2.14) are discretised using the scheme given in the seminal paper by Jean [17] and summarized in [24].

For the time-step $\Delta t$, the dummy variable $\alpha$ and $t_{n+\alpha}=t_{n}+\alpha \Delta t$, we introduce the following linear interpolations:

$$
\left\{\begin{array}{l}
\mathbf{x}_{n+\alpha}\left(\mathbf{k}_{x}\right)=\mathbf{x}_{n}+\alpha \Delta t \mathbf{k}_{x} \\
\mathbf{v}_{n+\alpha}\left(\mathbf{k}_{v}\right)=\mathbf{v}_{n}+\alpha \Delta t \mathbf{k}_{v}
\end{array}\right.
$$


Equation (4.1) yields the position at time $t_{n+\alpha}$ as a function of the position at time $t_{n}$ and the unknown velocity $\mathbf{k}_{x}$. Similarly, Eq. (4.2) yields the velocity at time $t_{n+\alpha}$ as a function of the velocity at time $t_{n}$ and the unknown acceleration $\mathbf{k}_{v}$. The dummy variable $\alpha \in\left[\frac{1}{2}, 1\right]$ stands either for $\theta$ or $\gamma$ in the time-stepping scheme presented below.

The chosen time-discretization of Eqs. (2.12), (2.13) and (2.14) is, term by term:

$$
\left\{\begin{array}{l}
\mathbf{M}\left(\mathbf{x}_{n+\theta}\left(\mathbf{k}_{x}\right)\right) \mathbf{k}_{v}=\mathbf{F}^{\star}\left(\mathbf{x}_{n+\theta}\left(\mathbf{k}_{x}\right), \mathbf{v}_{n+\theta}\left(\mathbf{k}_{v}\right), t_{n+\theta}\right)+\mathbf{H}\left(\mathbf{x}_{n+\gamma}\left(\mathbf{k}_{x}\right)\right) \mathbf{r} \\
\mathbf{v}_{n+\theta}\left(\mathbf{k}_{v}\right)=\mathbf{k}_{x} \\
\left(\mathbf{g}\left(\mathbf{x}_{n+\gamma}\left(\mathbf{k}_{x}\right)\right), \mathbf{H}^{\top}\left(\mathbf{x}_{n+\gamma}\left(\mathbf{k}_{x}\right)\right) \mathbf{v}_{n+\gamma}\left(\mathbf{k}_{v}\right), \mathbf{r}\right) \in K
\end{array}\right.
$$

where the unknowns are $\mathbf{k}_{x}, \mathbf{k}_{v}$ and the reaction forces $\mathbf{r}$, all of them to be considered at the $n+1$-th iterate. The numerical parameter $\theta^{3}$ controls the stability of the numerical scheme for the smooth dynamics; here $\theta=1$. The numerical parameter $\gamma$ relates to the non-smooth events; here, $\gamma=1$ which means that constraints are satisfied at the end of every time step.

Using (4.4), $\mathbf{k}_{x}$ can be eliminated in (4.3) and (4.5). The remaining unknowns are $\mathbf{k}_{v}$ and $\mathbf{r}$. Then, the contact kinematics $\mathbf{H}$ and the smooth dynamics $\left(\mathbf{M} \mathbf{k}_{v}\right.$ and $\left.\mathbf{F}^{\star}\right)$ in Eq. (4.3) are linearised around the preceding iterate of $\mathbf{k}_{v}$. Using a Newton loop results in a so-called One-Step Non-Smooth Problem ([1]) where $\mathbf{k}_{v}$ can be eliminated in Eq. (4.5) yields an algebraic inclusion of unknown $\mathbf{r}$ (for the first time step, $\mathbf{r}=\mathbf{0}$ ). This inclusion can be reformulated using an augmented Lagrangian and solved with a Gauss-Seidel-like algorithm (see [33], Chap. 4).

Currently, XDE performs force-driven simulations directly whereas position-driven simulations are performed by inserting a proportional-derivative corrector. Experimentally, this situation was mirrored by the insertion of a piston (see Sect. 3) which displays approximately a linear viscoelastic behaviour.

Another current limitation is that the nonlinear law of Eq. (2.6) is implemented by adjusting the stiffness and viscosity coefficients of the linear element "V" at each time step. These two limitations are by no way intrinsic to the methods used in XDE and are to be lifted in future versions.
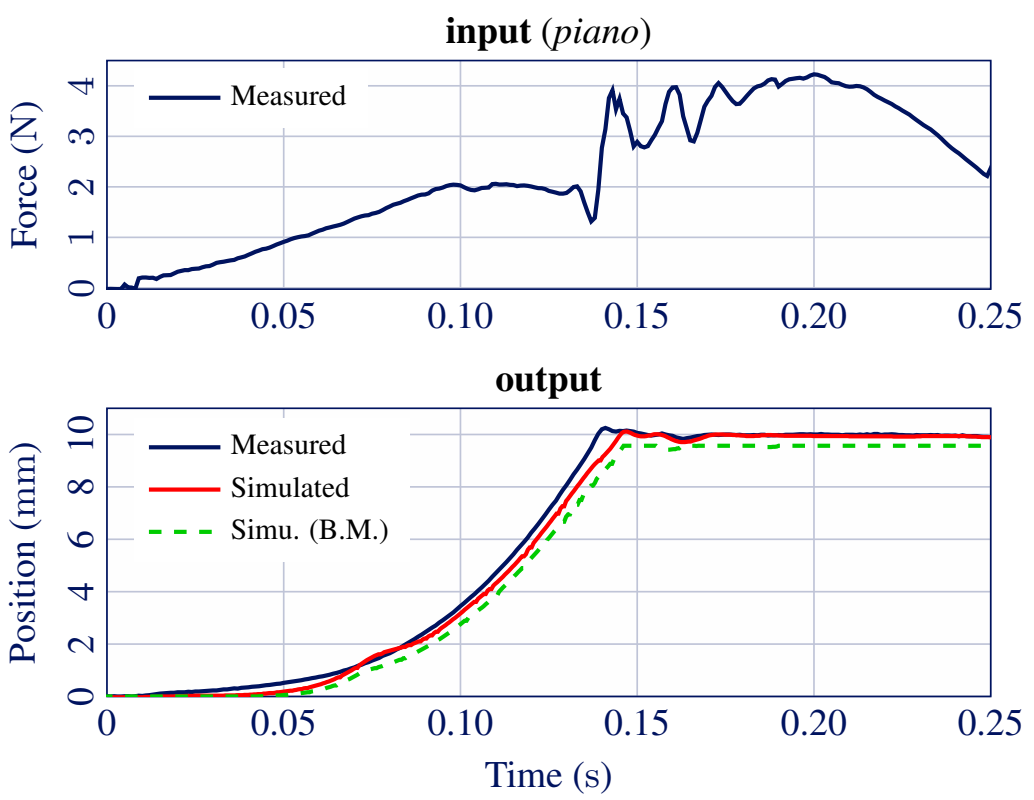

Figure 7: Measured and simulated positions of the key-end, for a piano keystroke (force-driven simulations).

5. Results and discussion Because of its extreme sensitivity to geometrical alterations, every piano action has to be regulated by a technician. This sensitivity is reflected in our model, hence the latter was preliminarily adjusted by hand using a common regulation procedure (see Appendix A of [36]).

${ }^{3}$ Even though it is not related to the angle of Eqs (2.2)-(2.5), the notation $\theta$ is used here to conform with the standard notation in numerics. 
The model is validated in both force-driven simulations and position-driven simulations by comparing simulated to measured positions and forces at the end of the key. In order to exemplify the conclusions of [37], we introduce a variation of the model by making the felts rigid (from now on, referred to as the Bad Model or BM). Of course, doing so on a piano action would be calamitous and the hammer would probably not even reach the string when the key is pressed down.

The calculated position in response to a force-driven piano keystroke is plotted in Figure 7 . The smoothening effect of the piano action is clear: the position outputs are much smoother than the force signal and the estimation of the measured position is good. The relative error of the model, defined as the ratio of the integral of the absolute value of the difference and the integral of the reference signal, is $3 \%$. The results of the Bad Model are almost as good (error: 9\%) showing, in line with the conclusions of [37], that force-driven simulations are virtually insensitive to the quality of the model.
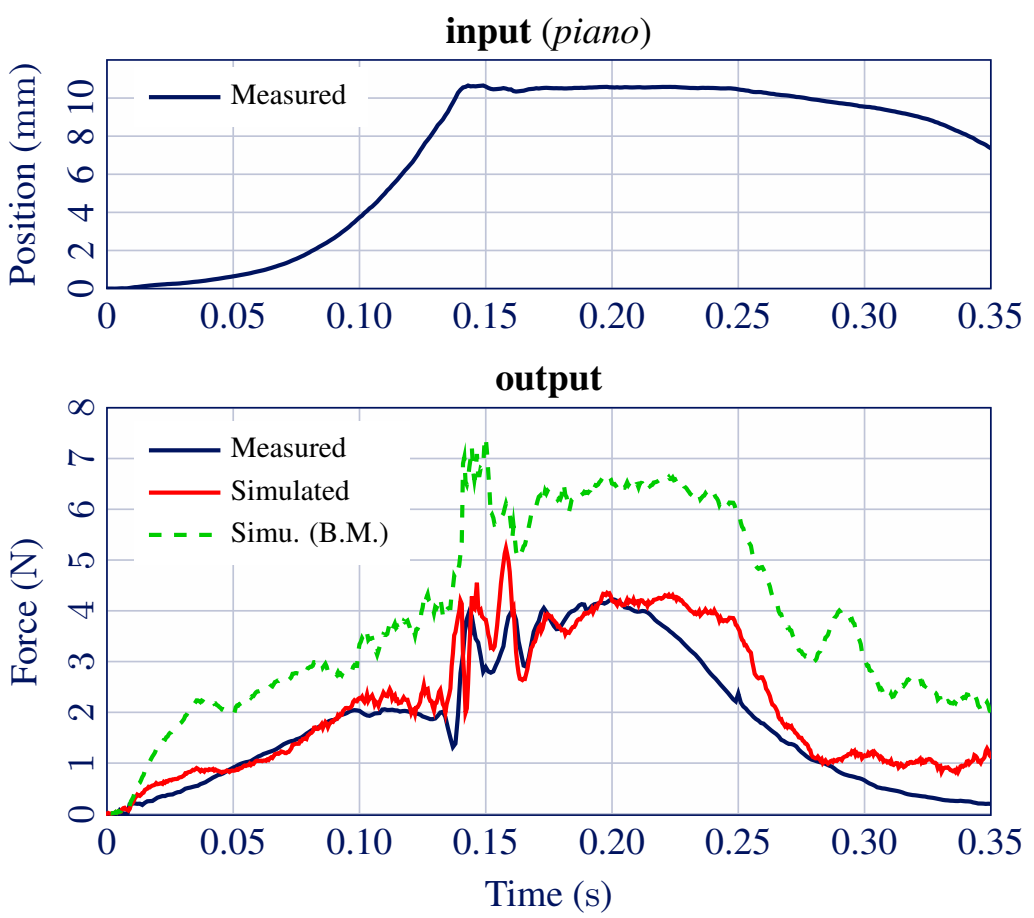

Figure 8: Measured and simulated reaction forces at the end of the key for a piano keystroke (positiondriven simulation).

The results of position-driven simulations are plotted in Figures 8 and 9. One notes that the time evolution of the (measured) position is very smooth and does not reveal much information on the dynamic complexity of the piano action. On the contrary, both the measured and simulated force display many irregularities, corresponding to non-smooth events (contact activation and stick-slip transitions) which occur during the keystroke. Despite this complexity in the profile of the results, the prediction of the model is very close to the measurements in the first phase (descent of the key), by far the most complex one, and the one that matters most for the pianist.

The holding phase (when the finger maintains the key in the down-position) is not rendered correctly in the position-driven simulations. This is not too surprising for a quasi-static phase. Presumably, this is mostly due to the discrepancy between the real behaviour of the piston (introduced between the finger and the key, see Sect. 3) and the ideal viscoelastic behaviour which would correspond to the proportionalderivative corrector (added to the model of the piano action, see Sect. 4). Another source of discrepancy between the simulated and the observed forces during the holding phase is that it is difficult to maintain a pure vertical force on the piston once the key has been blocked by the punch-rail. Since the piston has its own 3D-mobility, it is probable that the top and the bottom of the piston encounter different motions so that the input of the simulation does not correspond to the real motion-input. Since this point is a minor artefact of the simulation method, ${ }^{4}$ this discrepancy was not investigated further.

\footnotetext{
${ }^{4}$ In the scheduled future versions of the simulation software, a direct motion-input is possible, eliminating the need for the piston.
} 

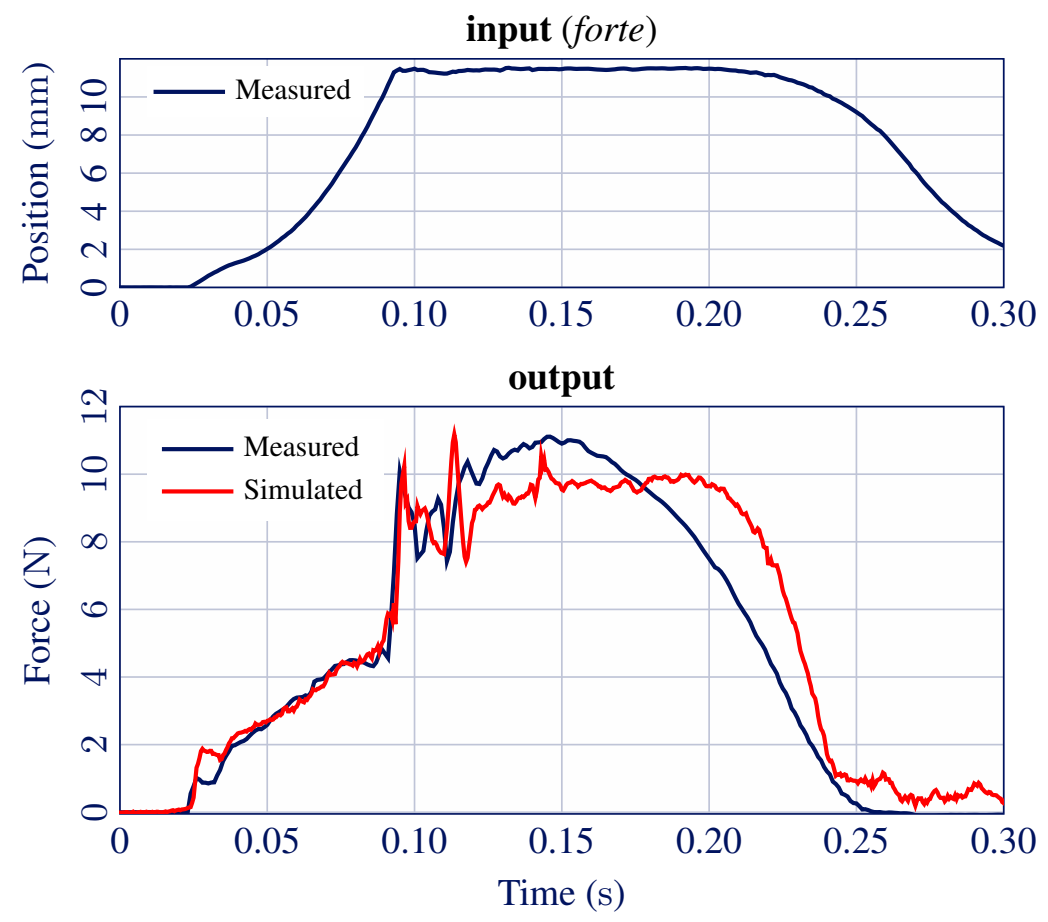

Figure 9: Measured and simulated reaction forces at the end of the key for a forte keystroke (positiondriven simulation).

As opposed to the force-driven simulations, the force simulated according to the Bad Model is off the measured force which is what is expected of a "Bad Model".

The escapement velocity of the hammer determines the intensity of the produced sound, and is therefore of great importance. Tab. 5 gathers the values obtained from the measurements and the simulation, for piano and forte dynamics. The prediction is very good.

\begin{tabular}{lll}
\hline Dynamics & Experimental $\left(\mathrm{m} \mathrm{s}^{-1}\right)$ & Simulated $\left(\mathrm{m} \mathrm{s}^{-1}\right)$ \\
piano & 1.01 & 1.00 \\
forte & 1.56 & 1.56 \\
\hline
\end{tabular}

Table 5: Velocity of the hammer at the escapement.

In Figure 10, the simulated positions of the different bodies are compared to their experimental estimations using the KLT tracking algorithm (see Sect. 3.2). Because of the limited resolution of our high-speed camera, angular measurement errors are significant: red dots in Fig. 6 are not perfectly tracked. As explained in Sect. 3, these measurements are rather intended to compare the time instants of non-smooth events, namely:

(a) beginning of contact between jack and let-off button punching;

(b) beginning of contact between key and front rail punching;

(c) contact between hammer and string;

(d) catch of the hammer;

(e) return of the jack to its resting position.

It appears in Figure 10 that the simulation catches these non-smoothnesses well. This explains why most irregularities of the forces in Figs. 8 and 9 are captured by the model.

By means of CAD software, we also built a parametric virtual piano action based on the geometrical description of the real action. This made visual inspection of the motion possible, and opens doors to easier understanding of the functioning of the action as well as helping innovating design. Screenshots of the most significant events are represented in Fig. 11. They compare very well with the pictures obtained with the high speed camera.

The characteristic time of the piano action is about a few milliseconds. All the simulation results have been calculated with a time step of $0.5 \mathrm{~ms}$ ( $2 \mathrm{kHz}$ : red curve in Figure 12). Results obtained with different 

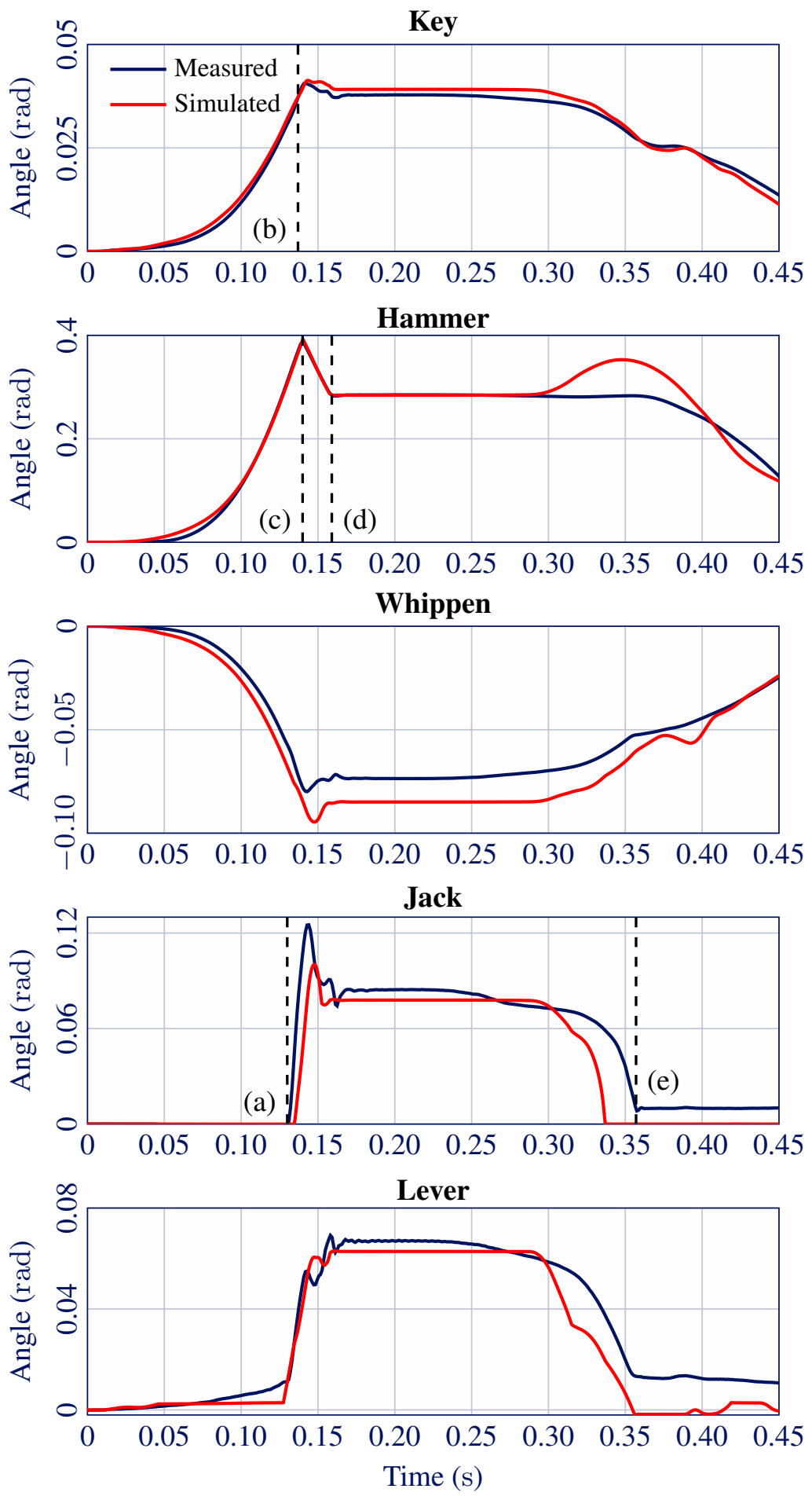

Figure 10: Kinematic results for a position-driven simulation, piano keystroke.

time steps are represented in Fig. 12. They do not significantly differ between $2 \mathrm{kHz}$ and $10 \mathrm{kHz}$ and this convergence indicates that there is no need to run the simulations with a higher frequency than $2 \mathrm{kHz}$. This is a great advantage of the non-smooth methods chosen: there is no numerical parameter for impact or dry friction calling for a very small time-step.

6. Conclusion The model of the piano action that is presented in this paper overcomes several limitations of what was offered by the literature so far. (a) The strong nonlinearities in the action dynamics (shocks, dry friction) which were accounted for by regularization, are now formally described by a Measure Differential Inclusion (MDI). (b) The validation of the model is granted by position-driven simulations which prove far more reliable than the usual force-driven simulations. The holding phase was not captured very accurately, due most probably to methodological artefacts in the experimental set-up. (c) The non-smooth formalism 


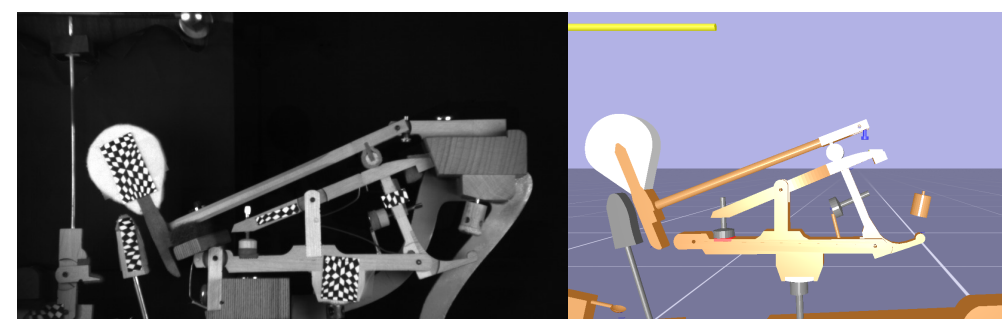

(a) At rest.

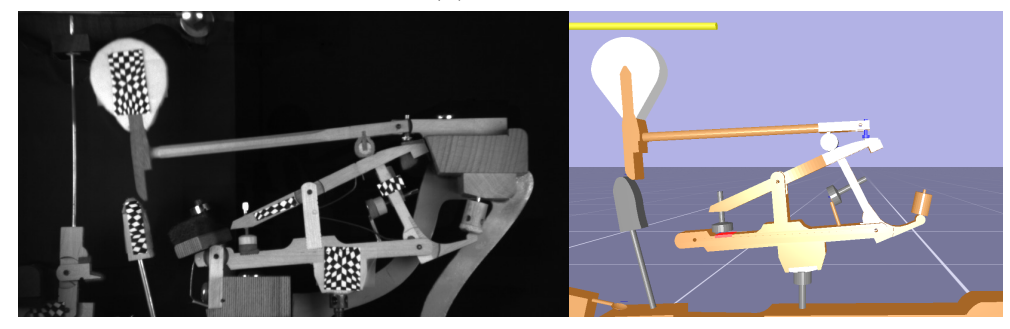

(b) Beginning of escapement.

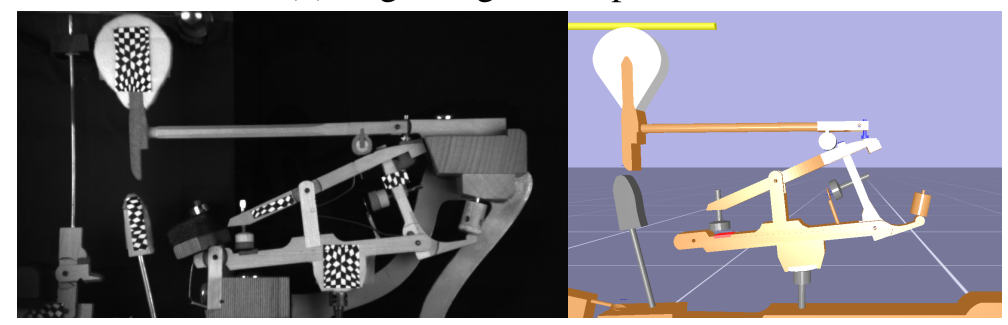

(c) Hammer-string impact.

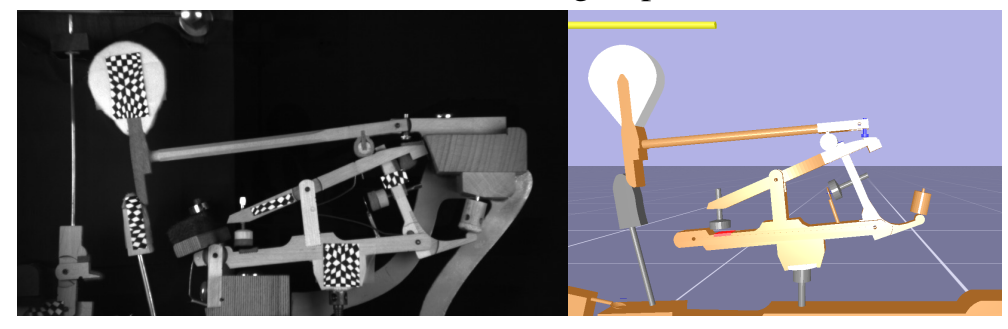

(d) Check catch.

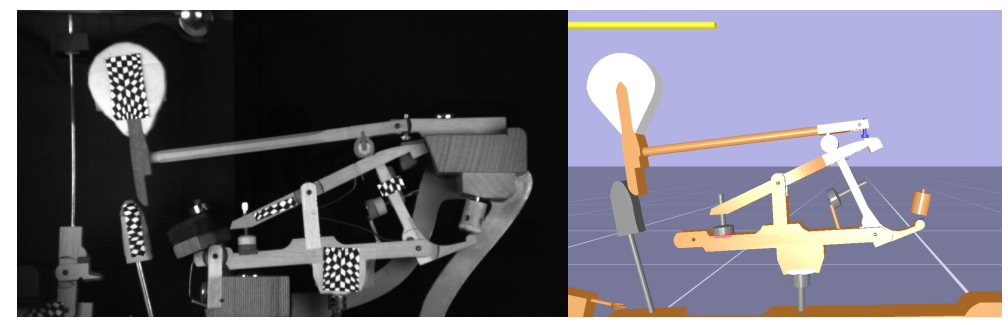

(e) Jack repositioning.

Figure 11: Film and simulation screenshots comparison for notable events. All the images correspond to the same keystroke. Each pair of images correspond to the exact same time instant.

proved to allow for simulations of about two orders of magnitude faster than the regularizing approach, as reported in the literature.

Minor improvements of the model include (a) taking into account the first mode of vibration of the hammer's shank by inserting a spring between the hammer's head and the knuckle and (b) introducing the felt underneath the key-bed.

In terms of performance, the simulations run about twenty times slower than real time on a 2010computer equipped with a $2.1 \mathrm{GHz}$ Intel Core i5. The future versions of the simulation software will allow direct position-driven simulation (thus eliminating the need for the proportional-derivative corrector and its approximate experimental counterpart), include a more efficient implementation of the nonlinear springs laws and perform direct 2D dynamics rather that 3D. Presumably, the resulting computing efficiency will be more than sufficient for a real-time computation of the piano action dynamics on a standard laptop. 


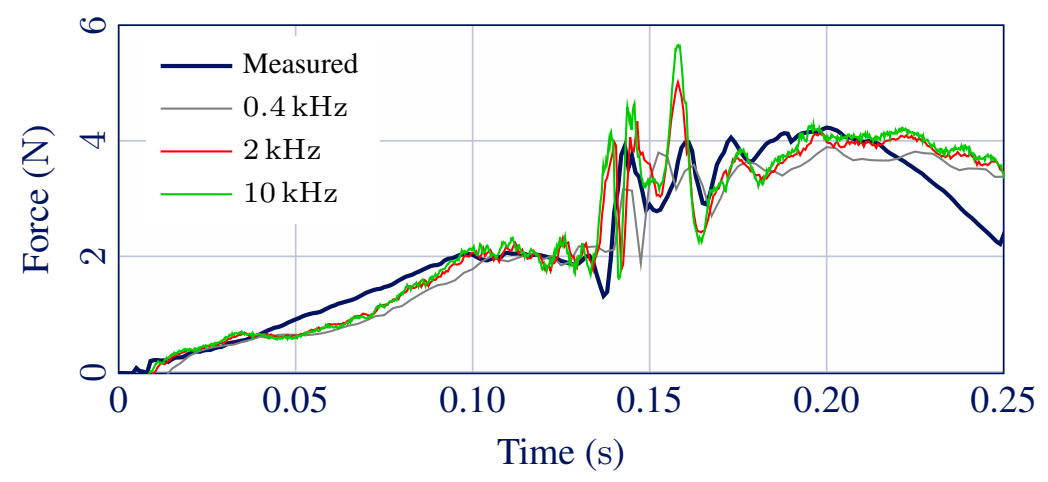

Figure 12: Simulated forces (in piano) for different time steps.

Practically, this will open doors to a large variety of applications, from numerical lutherie, innovative design, sensitivity analysis of the piano action, to real-time haptic investigations.

\section{References}

[1] ACARY, Vincent, BROGLIATO, Bernard. Numerical methods for nonsmooth dynamical systems: applications in mechanics and electronics. Volume 35. Springer, 2008. [ISBN: 9783540753926]. [inria-00423530].

[2] AsKenfelt, Anders, JANSSON, Erik. From touch to string vibrations. II: the motion of the key and hammer. The Journal of the Acoustical Society of America 90:2383, 1991. [10.1121/1.402043].

[3] Barbacci, Adelin, Diener, Julien, Hémon, Pascal, Adam, Boris, Donès, Nicolas, Reveret, Lionel, Moulia, Bruno. A robust videogrametric method for the velocimetry of wind-induced motion in trees. Agricultural and Forest Meteorology 184:220-229, 2014. [10.1016/j.agrformet.2013.10.003].

[4] Bokiau, Baudouin, Poncelet, Antoine, Fisette, Paul, DocQuier, Nicolas. "Multibody model of a grand piano action aimed at understanding and demystifying the escapement principle". The 2nd Joint International Conference on Multibody System Dynamics, 2012. [2078.1/130687].

[5] BoutiLLON, Xavier. Model for piano hammers: experimental determination and digital simulation. The Journal of the Acoustical Society of America 83(2):746-754, 1988. [10.1121/1.396117].

[6] Brenon, Céline. "Mécanique de la touche de piano (Piano action)". Master Thesis. Université Pierre et Marie Curie, Paris VI, 2002.

[7] ChABASSIER, Juliette, DuRUfLÉ, Marc. Energy based simulation of a Timoshenko beam in non-forced rotation. Influence of the piano hammer shank flexibility on the sound. Journal of Sound and Vibration 333(26):7198-7215, 2014. [hal-00918635].

[8] ChaRTRAND, Rick. Numerical differentiation of noisy, nonsmooth data. ISRN Applied Mathematics, 2011. [10.5402/ 2011/164564].

[9] DiJKsterhuis, PR. De piano. Nederlandse Akoest. Genootschap 7:50-65, 1965.

[10] Gillespie, Brent, Yu, Bo, Grijalva, Robert, AwtaR, Shorya. Characterizing the feel of the piano action. Computer Music Journal 35(1):43-57, 2011. [10.1162/COMJ_a_00039].

[11] Hayashi, Eiji, Yamane, Masami, Mori, Hajime. Behavior of piano-action in a grand piano. I. Analysis of the motion of the hammer prior to string contact. The Journal of the Acoustical Society of America 105:3534, 1999. [10.1121/1.424678].

[12] HiRSCHKORN, Martin. "Dynamic model of a piano action mechanism". PhD thesis. University of Waterloo, 2004.

[13] HirschKorn, Martin, MCPhee, John, Bir Kett, Stephen. Dynamic modeling and experimental testing of a piano action mechanism. Journal of computational and nonlinear dynamics 1(1):47-55, 2006. [10.1115/1.1951782].

[14] ITÔ, Kiyosi. Encyclopedic dictionary of mathematics. Volume 1. MIT press, 1993.

[15] IZADBAKHSH, Adel. "Dynamics and control of a piano action mechanism". Master thesis. University of Waterloo, 2006.

[16] Izadbakhsh, Adel, McPhee, John, Birkett, Stephen. Dynamic modeling and experimental testing of a piano action mechanism with a flexible hammer shank. Journal of computational and nonlinear dynamics 3(3), 2008. [10.1115/1.2908180].

[17] JeAN, Michel. The non-smooth contact dynamics method. Computer methods in applied mechanics and engineering 177(3):235-257, 1999. [10.1016/S0045-7825(98)00383-1].

[18] JeAn, Michel, MoReau, Jean-Jacques. Dynamic of elastic or rigid bodies with frictional contact: numerical methods. Mécanique, Modélisation Numérique et Dynamique des Matériaux, 1991.

[19] LeISSA, Arthur. The historical bases of the Rayleigh and Ritz methods. Journal of Sound and Vibration 287(4):961-978, 2005. [10.1016/j.jsv.2004.12.021].

[20] LinKs, Harmen. "Modeling of a grand piano action mechanism". Master Thesis. Delft University of Technology, 2011.

[21] LoZADA, José. "Modeling, haptic control and novel concepts for musical keyboards". PhD thesis. École Polytechnique, 2007. [tel-00280538]. 
[22] LUCAS, Bruce, KANADE, Takeo. "An iterative image registration technique with an application to stereo vision." Proceeding of the 7th International Joint Conference on Artificial Intelligence. 1981.

[23] MAsoudi, Ramin, BIRKETT, Stephen. Experimental validation of a mechanistic multibody model of a vertical piano action. Journal of Computational and Nonlinear Dynamics 10(6):061004, 2015. [10.1115/1.4028194].

[24] Merlhiot, Xavier. "On some industrial applications of time-stepping methods for nonsmooth mechanical systems: issues, successes and challenges". Euromech Colloquium [516]-Nonsmooth contact and impact laws in mechanics. 2011.

[25] Merlhiot, Xavier, Le GArrec, Jérémie, SAupin, Guillaume, Andriot, Claude. "The XDE mechanical kernel: efficient and robust simulation of multibody dynamics with intermittent nonsmooth contacts". The 2nd Joint International Conference on Multibody System Dynamics, 2012.

[26] MORI, Taro. "A comparison between upright and grand pianos". Volume 83. Journal of the European Acoustics Association, 1997.

[27] Овов, Roberto. A multi-instrument, force-feedback keyboard. Computer Music Journal 30(3):38-52, 2006. [10.1162/ comj.2006.30.3.38].

[28] OledZKI, Anatoli. Dynamics of piano mechanisms. Mechanism and Machine Theory 7(4):373-385, 1973. [10.1016/0094$114 X(72) 90047-X]$.

[29] Principeaud, Nicolas, Boutillon, Xavier. Reproducibility of piano playing. The Journal of the Acoustical Society of America 123(5):3125-3125, 2008.

[30] Rockafellar, Tyrrell. Convex Analysis (Princeton Mathematical Series). Volume 46. 1970: 49. [ISBN: 9780691015866].

[31] Southwell, RV. XVI. On Castigliano's theorem of least work, and the principle of St. Venant. The London, Edinburgh, and Dublin Philosophical Magazine and Journal of Science 45(265):193-212, 1923. [10.1080/14786442308634103].

[32] STEWART, David. Rigid-body dynamics with friction and impact. SIAM review 42(1):3-39, 2000. [10 . 1137 / S0036144599360110].

[33] Studer, Christian. Numerics of Unilateral Contacts and Friction. Volume 47. Springer, 2009. [ISBN: 783642011009].

[34] Stulov, Anatoli. Experimental and computational studies of piano hammers. Acta Acustica united with Acustica 91(6):1086-1097, 2005.

[35] Technical Manual - The hornbeam advantage. Renner. 2014.

[36] ThORIN, Anders. "Non-smooth model of the grand piano action". PhD thesis. École Polytechnique, 2013. [pastel00939493].

[37] Thorin, Anders, Boutillon, Xavier, LozAdA, José. Modelling the dynamics of the piano action: is apparent success real? Acta Acustica united with Acustica 100(6):1162-1171, 2014. [hal-01193708].

[38] Tomasi, Carlo, Kanade, Takeo. Detection and tracking of point features. School of Computer Science, Carnegie Mellon University, 1991.

[39] VAn Den Berghe, Guido, De Moor, Bart, Minten, Willem. Modeling a grand piano key action. Computer Music Journal 19(2):15-22, 1995. [10.2307/3680597].

[40] Vyas ARAyAni, Chandrika P, BirketT, Stephen, McPhee, John. Modeling the dynamics of a compliant piano action mechanism impacting an elastic stiff string. The Journal of the Acoustical Society of America 125:4034, 2009.

\section{A. Models for estimating the rigid body approximation for the key and the}

hammer The purpose of this appendix is to give the details of the estimation, for the key and the hammer, of:

- their first modal frequency (dynamics);

- their flexibility as linear elastic bodies compared the the flexibility of the felts (statics).

Four different models were considered in total: two for each piece, see Fig. 13.

The first mode of vibration was approximated using the Rayleigh-Ritz method (see for example [19]). The mass of the key was assumed to be equally distributed while for the hammer, it was assumed to be concentrated at the center of the hammer head. The static deformations $\varphi_{\text {key }}, \varphi_{\text {hammer }}$ in response to the corresponding weight were calculated and used as the shape functions for the Rayleigh quotient. With point $O$ corresponding to the origin of the $x$-axis, the calculated expressions are:

$$
\varphi_{\text {key }}(x)= \begin{cases}\frac{1}{24 E I L_{2}}\left(-2 L_{1}^{2}\left(L_{2}^{2}-x^{2}\right)+L_{2}\left(L_{2}^{3}-2 L_{2} x^{2}+x^{3}\right)\right. & \text { for } x \in\left[0, L_{2}\right] \\ \frac{1}{24 E I}\left(L_{2}-x\right)\left(2 L_{2}^{3}+2 L_{1}^{2}\left(L_{2}-3 x\right)+4 L_{1}\left(L_{2}-x\right)^{2}-3 L_{2}^{2} x+3 L_{2} x^{2}-x^{3}\right) & \text { for } x \in\left(L_{2}, L 1+L 2\right]\end{cases}
$$

and

$$
\varphi_{\text {hammer }}(x)= \begin{cases}\frac{L_{1}}{6 E I L_{2}} x\left(L_{2}-x\right)\left(L_{2}+x\right) & \text { for } x \in\left[0, L_{2}\right] \\ \frac{-1}{6 E I}\left(L_{1}\left(L_{2}-3 x\right)+\left(L_{2}-x\right)^{2}\right)\left(L_{2}-x\right) & \text { for } x \in\left(L_{2}, L 1+L 2\right]\end{cases}
$$




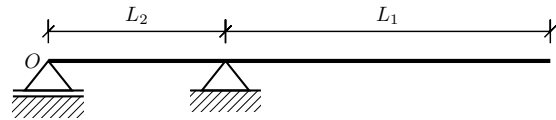

(a) Elastic key model.

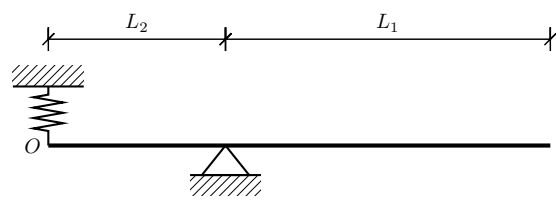

(c) Rigid key model.

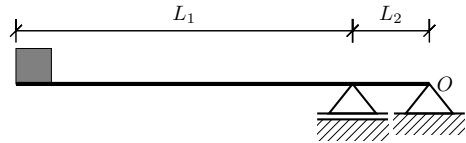

(b) Elastic hammer model.

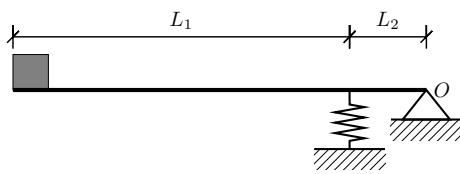

(d) Rigid hammer model.

Figure 13: Models used for investigating the rigid body approximation of the key and the hammer. (a) Beam model of the key. (b) Beam model of the hammer shank. (c) Rigid key in contact with the felt of the blocked whippen. (d) Rigid hammer in contact with the felt of the knuckle and the blocked jack. The sliding hinge joint element in (a) and (b) blocks translation in the out-of-plane direction only: it represents the whippen-key contact for the key (left) and the hammer roller-jack contact for the hammer (right).

An approximation of the frequency of the first eigenmode is $\sqrt{R} /(2 \pi)$ where $R$ is the Rayleigh quotient

$$
R=\frac{\int_{0}^{L_{1}+L_{2}} E I \varphi^{\prime \prime}(x)^{2} \mathrm{~d} x}{\int_{0}^{L_{1}+L_{2}} \rho S \varphi(x)^{2} \mathrm{~d} x}
$$

The calculations yield $f_{1, \text { key }}=355 \mathrm{~Hz}$ and $f_{1 \text {,hammer }}=39 \mathrm{~Hz}$.

The flexibilities $\psi_{\mathrm{key}}^{\mathrm{e}}$ hammer of the key as seen from the finger, or of the hammer as seen from the hammer head, and due to the elasticity of wood, can be estimated with the same models (see Fig. 13 (a), (b)). The strain energy $U$ of the beams for a force $F$ applied at position $L_{1}+L_{2}$ is given by the integration of the squared moment over the length, divided by $2 E I$; it comes:

$$
U=\frac{F^{2}}{6 E I} L_{1}^{2}\left(L_{1}+L_{2}\right)
$$

The flexibility $\psi^{\mathrm{e}}$ is given by Castigliano theorem (see for example [31]):

$$
\psi^{\mathrm{e}}=\frac{1}{3 E I} L_{1}^{2}\left(L_{1}+L_{2}\right)
$$

With $L_{1}=0.18 \mathrm{~m}, L_{2}=0.13 \mathrm{~m}$ for the key and $L_{1}=0.13 \mathrm{~m}, L_{2}=0.016 \mathrm{~m}$ for the hammer, the flexibilities for the elastic model with rigid boundary conditions are $\psi_{\mathrm{key}}^{\mathrm{e}}=1.5 \times 10^{-5} \mathrm{~m} \mathrm{~N}^{-1}$ and $\psi_{\text {hammer }}^{\mathrm{e}}=1.2 \times 10^{-3} \mathrm{~m} \mathrm{~N}^{-1}$ (the value of the other parameters is given in Tab. 3).

The flexibilities $\psi_{\text {location }}^{\mathrm{f}}$ due to felts only, estimated at a given location, come as follows: each beam is considered rigid, with its motion limited by nearby felts (see Fig. 13 (c), (d)). For the nonlinear felt law given in Eq. (2.6), the average flexibility is

$$
\psi_{\text {felt }}^{\mathrm{f}}=\frac{\delta}{F_{\text {felt }}}=k^{(-1 / r)} F_{\text {felt }}^{(1-r) / r}
$$

The ratio of the flexibilities at the finger end of the key (respectively, at the hammer's head) and at the corresponding felt (whippen and knuckle, respectively) is $\psi_{\text {key, hammer }}^{\mathrm{f}} / \psi_{\text {felt }}^{\mathrm{f}}=\lambda^{2}$ where $\lambda=L_{1} / L_{2}$ (respectively $\left.\left(L_{1}+L_{2}\right) / L_{2}\right)$. Since the force applied at the finger end (respectively at the hammer's head position) is $F_{\text {key, hammer }}=F_{\text {felt }} / \lambda$, it comes

$$
\psi_{\text {key, hammer }}^{\mathrm{f}}=k^{(-1 / r)} \lambda^{(r+1) / r} F_{\text {key, hammer }}^{(1-r) / r}
$$

Since the felts are nonlinear springs, it is normal that the flexibility depends on the force level.

For the key, $5 \mathrm{~N}$ represents a typical force level exerted by the finger. For the hammer, the mass is concentrated at its head. With a mass of $12 \mathrm{~g}$, typical of the bass hammers, a forte keystroke corresponds 
to a displacement of $5 \mathrm{~cm}$ of the head in about $20 \mathrm{~ms}$, hence an average inertia force $F=3 \mathrm{~N}$ at the head position. With the parameters values $k=1.6 \times 10^{10} \mathrm{uSI}$ and $r=2.7$ for the whippen-key felt and $k=7 \times 10^{9} \mathrm{uSI}$ and $r=3$ for the knuckle's felt, the flexibilities are $\psi_{\mathrm{key}}^{\mathrm{f}}=9.5 \times 10^{-5} \mathrm{~m} \mathrm{~N}^{-1}$ and $\psi_{\text {hammer }}^{\mathrm{f}}=4.8 \times 10^{-3} \mathrm{~m} \mathrm{~N}^{-1}$. For lower force levels, the flexibilities are larger since the felts are hardening springs. 